\title{
Effect of Individual Components of Lignocellulosic Biomass on Methane Production and Methanogen Community Structure
}

\author{
Tomasz Pokój $^{1} \cdot$ Ewa Klimiuk $^{1} \cdot$ Katarzyna Bułkowska $^{1} \cdot$ Przemysław Kowal $^{2}$ [D $\cdot$ Slawomir Ciesielski ${ }^{1}$
}

Received: 14 March 2018 / Accepted: 22 August 2018 / Published online: 24 August 2018

(c) The Author(s) 2018

\begin{abstract}
One of the major factors that influences the economic feasibility of biogas production is the availability of digestible feedstocks. There is little research on the influence of the chemical composition of biomass on biogas synthesis, especially with regard to the content of lignocellulosic materials. Therefore, the aim of this study was to estimate how differences in the content of cellulose and lignin in lignocellulosic biomass influence the concentrations of individual volatile fatty acids (VFAs) and biogas production. Additionally, the structure of the methanogenic community was examined. The removal of fibrous and non-fibrous materials, the concentrations of individual VFAs, methane production and methanogen community structure were examined during digestion of Zea mays L. and Miscanthus sacchariflorus silages. Organics were removed with higher efficiency during the digestion of $Z$. mays silage than during digestion of $M$. sacchariflorus. This was due to the higher non-fibrous carbohydrates content in Z. mays than in M. sacchariflorus. In both digesters, propionate predominated throughout experiment. The methanogenic community in the digester fed with Z. mays was more diverse than that in the digester with M. sacchariflorus. Analysis of 16S rRNA sequences showed that six acetoclastic and four hydrogenotrophic methanogens were present in the digester fed with Z. mays L., while five acetoclastic and three hydrogenotrophic methanogens were in the digester fed with M. sacchariforus. The abundance of Methanosarcina correlated significantly with the concentration of all analyzed VFAs.
\end{abstract}

Keywords Crop silage - Anaerobic digestion - Syntrophic volatile fatty acids oxidation · Archaeal community structure · Methane yield

\section{Statement of Novelty}

To introduce novel biomass types for biogas production, an integrated evaluation approach has to be applied. The present study delivers a combination of technological and microbial data about the process of anaerobic digestion of the commonly used substrates Zea mays L. silage and Miscanthus sacchariflorus silage, the latter of which has a high content of lignin and cellulose. The correlations between the abundance of methanogenic microorganisms and the

Przemysław Kowal

przkowal@pg.edu.pl

1 Department of Environmental Biotechnology, University of Warmia and Mazury in Olsztyn, Słoneczna Str. 45G, 10-719 Olsztyn, Poland

2 Faculty of Civil and Environmental Engineering, Gdansk University of Technology, Narutowicza Street 11/12, 80-233 Gdansk, Poland concentrations of individual VFAs produced during digestion of these substrates were estimated. The results reveal novel associations between the type of substrate used, the rate of methane production and the structure of the methanogenic community. The use of materials with a high lignin content limits biodiversity in the anaerobic digesters, which can result in decreases in anaerobic digestion performance and biogas production.

\section{Introduction}

Anaerobic digestion (AD) is an important technology for simultaneously utilizing waste and producing biogas. Food waste, municipal solid waste and animal manure are commonly transformed in this manner. Recently, energy crops and crop residues have gained much attention as substrates, mainly due to their abundance. By using perennial crops that are cultivated on marginal and agro-technical lands that are 
not suitable for producing food, it may be possible to reduce the competition for land between food and energy crops, and mitigate the currently observed increase in demand from the bioenergy sector for vegetable food feedstocks.

$\mathrm{AD}$ of organics to methane is a complex process involving at least four different microbial groups: primary fermenting bacteria, secondary fermenting bacteria, and two types of methanogens. Hydrolysis and fermentation are the key stages in reducing the amount of the solid phase and supplying volatile fatty acids (VFAs), which are favorable precursors for the next steps. The pathways leading to formation of individual VFAs depend on several factors, such as the chemical composition of substrate and the operational conditions of digestion [1]. It is commonly believed that an increase in the concentration of VFAs can lead to process failure. One of the most common reasons for process deterioration is reactor acidification due to reactor overload. For this reason, many studies have focused on the relationship between VFAs accumulation and organic loading rate [2].

The effect of the chemical composition of biomass on the build-up of VFAs, particularly with regard to the presence of lignocellulosic materials in the biomass, has received little attention. It is commonly known that acetate and propionate are the main intermediates in the degradation of polysaccharides such as starch or cellulose. Valerate may form as intermediate of L-arabinose and D-xylose fermentation, which are present in the largest amount in hemicelluloses. Branched-chain fatty acids, such as isobutyrate, isovalerate and 2-methylbutyrate, are products of protein degradation [2].

In a complex methanogenic community, some volatile fatty acids can be synthesized from two acids that are present together, or reversible isomerization between isoforms can take place. For example, Wu et al. [3] found that, during conversion to methane, reversible isomerisation between butyrate and isobutyrate took place, and that when butyrate was degraded in the presence of propionate, isobutyrate was synthesized from butyrate and 2-methylbutyrate from propionate. A literature review shows that, in many cases, the appearance of acid isoforms in the digestate leads to the uncoupling of acid formation and conversion of the acids to methane.

In anaerobic digesters, methane production is favored by syntrophic interactions between fermenting bacteria and methanogens. Franke-Whittle et al. [4] found that, when a mixture of cow manure (46\%), corn silage (36\%), vegetable waste (9\%) and potato (9\%) was digested under mesophilic conditions, the quantity of Methanosarcina correlated positively with the concentrations of all VFAs, whereas the abundance of Methanobacterium was not affected by VFA concentration. However, when a mixture of cow manure $(52 \%)$ and food waste $(48 \%)$ was digested in thermophilic conditions, the abundance of Methanosarcina only had a significant positive correlation with the concentrations of acetate, butyrate and isovalerate, while Methanobacterium abundance had a significant negative correlation with the same VFAs. According to the authors, the concentrations of VFAs are not the only criteria that determine the dominance of a particular genera of methanogens. However, the results of those authors do suggest the need for further research that uses statistical analyses to estimate the association between the type and concentration of VFAs and the structure of the methanogenic community.

Therefore, the aim of this study was to investigate how two kinds of lignocellulosic biomass that differ in their content of cellulose and lignin influence the concentrations of individual VFAs and the structure of the methanogenic community. Silages of Z. mays L. and M. sacchariflorus were anaerobically digested under constant operational conditions. Z. mays L. was chosen as a model crop because it is commonly used in agricultural biogas plants, and M. sacchariflorus because of its high content of fibrous materials, including lignin. The following variables were measured: (i) the removal of individual non-fibrous and fibrous materials, (ii) the concentrations of individual VFAs that are fermentation intermediates, (iii) the Archaeal community structure in digesters, using the polymerase chain reaction coupled with denaturing gradient gel electrophoresis (PCR-DGGE), and (iv) the rate of biogas and methane production. The observed and theoretical methane yield coefficients were calculated, and Pearson product-moment correlation coefficients were calculated to estimate the associations between the concentrations of individual VFAs and the abundance of methanogens.

\section{Methods}

\section{Feed Material}

Zea mays L. and M. sacchariflorus were used as substrates for biogas production. They were obtained during field experiments at the Production and Experimental Station in Bałcyny $\left(53^{\circ} 35^{\prime} 49^{\prime \prime} \mathrm{N}, 19^{\circ} 51^{\prime} 20.3^{\prime \prime} \mathrm{E}\right)$, belonging to the University of Warmia and Mazury in Olsztyn (Poland).

Zea mays L. (mid-early variety LG 3232) was harvested at the BBCH 89 stage (fully ripe: kernels hard and shiny), and $M$. sacchariflorus (clone variety) at the beginning of the ejection phase of the panicle in the fourth year of vegetative growth. The crops were collected by self-propelled harvesters equipped with cutting drums, which chopped the crops into $2-3 \mathrm{~cm}$ long pieces. Both kinds of harvested biomass were then ensiled by concentrating them in $200 \mathrm{~L}$ silos lined with foil for 90 days. Formic acid $(85 \%)$ was added at a ratio of $5 \mathrm{~g}$ of acid per $1 \mathrm{~kg}$ of biomass. 


\section{Feedstock Preparation}

For feedstock standardization, the silages were dried at $60{ }^{\circ} \mathrm{C}$ and ground in a cutting mill (Retsch SM100, Germany), then passed through a $1-\mathrm{mm}$ screen and stored in plastic containers at room temperature. In the standardized silages, the concentrations of total solids (TS) and volatile solids (VS) were $968.0( \pm 5.0) \mathrm{g} \mathrm{kg}^{-1}$ and $902.0( \pm 4.0) \mathrm{g} \mathrm{kg}^{-1}$, respectively for Z. mays L., and $971.0( \pm 3.0) \mathrm{g} \mathrm{kg}^{-1}$ and $864.0( \pm 3.0) \mathrm{g} \mathrm{kg}^{-1}$, respectively, for M. sacchariflorus. The elemental composition of $Z$. mays $L$. silage included the following: C, $43.9 \%$;, $6.01 \%$;, $1.57 \%$; and $\mathrm{O}, 41.7 \%$; that of M. Sacchariflorus was as follows: C, $45.9 \%$; H, $5.61 \%$; $\mathrm{N}, 1.46 \%$; and $\mathrm{O}, 36.0 \%$. To prepare the feedstocks, $12.8 \mathrm{~g}$ of standardized Z. mays L. silage and $13.1 \mathrm{~g}$ of standardized M. sacchariflorus were weighed and mixed with $0.133 \mathrm{~L}$ distilled water to obtain a 9\% VS concentration in both feedstocks.

\section{Digester Performance}

The experiments were conducted simultaneously over 75 days in continuously-stirred anaerobic tank reactors (CSTRs) with a working volume of $6 \mathrm{~L}$, equipped with a stirrer and a water jacket. Valves located on the top and bottom of the reactor chamber enabled feeding and biogas/digestate collection. The reactors were inoculated with anaerobic sludge from the sludge digestion chambers of a municipal wastewater treatment plant. Once a day, $0.133 \mathrm{~mL}$ of digestate was withdrawn from each reactor and the same volume of feedstock (with 9\% VS concentration) was then added. One reactor was fed with Z. mays L. feedstock (R-ZM) and the second was fed with M. sacchariflorus feedstock (R-MS). To avoid sudden $\mathrm{pH}$ drops shortly after feedstock was added and to prevent reactor acidification, $\mathrm{NaOH}$ was added to the feedstock at a concentration of $0.5 \mathrm{~g} \mathrm{~L}^{-1}$ of feedstock during the first 10 days of the experiment. Both digesters were operated at a hydraulic retention time (HRT) of 45 days and an organic loading rate (OLR) of $2.07 \mathrm{~g} \mathrm{~L}^{-1} \mathrm{day}^{-1}$. The temperature was maintained at $39^{\circ} \mathrm{C}$.

\section{Analytical Methods}

TS and VS were measured according to standard methods for examination of water and wastewater [5]. Content of water soluble carbohydrates was measured by the anthrone method; that of raw protein (RP), by total organic nitrogen (the difference between total Kjeldahl nitrogen and total ammonium nitrogen) and multiplying by a factor of 6.25 . Content of raw lipids (RL) was found by Soxhlet extraction using petroleum ether as a solvent; that of raw fibre (RF), according to EN ISO 6865:2000 [6], and that of neutral detergent fiber, according to EN ISO 16472:2006 [7].
Nitrogen-free extract (NfE) was measured by subtracting the amounts of RP, RL and RF from VS [8]. The Van Soest procedure was used to measure the content of cellulose (Cel), hemicellulose (Hem) and lignin. The Van Soest extension introduces three fractions: neutral detergent fibre (NDF), acid detergent fibre (ADF) and acid detergent lignin (ADL). NDF is mainly composed of cellulose, hemicellulose and lignin; the main fractions in ADF are cellulose, lignin and ash from cell walls; whereas ADL includes lignin and acid insoluble ash.

Starch content was estimated by taking the difference between total carbohydrates (as the sum of RF and NfE) and NDF; the content of hemicellulose was calculated as the difference between NDF and ADF; whereas cellulose content, as the difference between ADF and ADL [8]. Content of non-fibrous carbohydrates (NFC) was calculated by summing the contents of starch and water-soluble carbohydrates.

The $\mathrm{C}, \mathrm{H}$ and $\mathrm{N}$ contents of the biomass were measured using a FLASH 2000 (Thermo Scientific). In the feedstocks, TS and VS were measured. In the liquid phase of the feedstocks, the following variables were measured: soluble chemical oxygen demand (CODs), ammonium and phosphates concentration (according to standard methods; [5]), $\mathrm{pH}$ (immediately after sampling using a $\mathrm{pH}$ meter Hanna HI 221, USA), total alkalinity (by titration to $\mathrm{pH} 4.3$ with normalized $0.1 \mathrm{M} \mathrm{HCl}$ using a Schott titroline system), and VFAs (using a gas chromatograph GC, Varian 3800, Australia) according to Gilroyed et al. [9]. The total concentration of VFAs was the sum of the concentrations of the individually analyzed VFAs. CODs, $\mathrm{pH}$, ammonium, alkalinity and VFAs were measured in filtered supernatant samples previously centrifuged at $8693 \times g$ for $10 \mathrm{~min}$. The biogas volume was measured using a gas meter (Aalborg, model XFM 17). Methane and carbon dioxide content were measured in samples collected in Tedlar bags by a GA2000 + automatic analyzer (Geotechnical Instruments). All measurements were performed daily.

\section{Molecular Analysis of the Structure of the Archaeal Community}

\section{DNA Extraction}

Genomic DNA was extracted from biomass samples collected from both reactors at the beginning of the experiments (day 0 ), then on days $5,8,12,15,22,33,36,50,57$ and 68 , and at the end of the experiments (day 75). DNA was extracted from the samples by the following steps: $0.1 \mathrm{~g}$ of biomass was washed in sodium phosphate buffer $(0.1 \mathrm{M}$; $\mathrm{pH}$ 8.0) and pelleted by centrifugation. After rejection of the supernatant, $1 \mathrm{~mL}$ of the extraction buffer $(100 \mathrm{mM}$ Tris-HCl; $100 \mathrm{mM}$ EDTA; $1.5 \mathrm{M} \mathrm{NaCl} ; \mathrm{pH} 8)$ and $0.3 \mathrm{~g}$ of glass beads $(\varnothing 0.25-0.5 \mathrm{~mm}$; Carl Roth, Karlsruhe, 
Germany) were added. Samples were then shaken for $20 \mathrm{~min}$ in a bead-beating device (Uniequip, Germany). Next, samples were incubated for one additional hour at $65{ }^{\circ} \mathrm{C}$ with $0.2 \mathrm{~mL}$ of the $10 \%$ SDS solution to improve lysis of the Archaeal cells. After centrifugation at $16,100 \times g$ for $10 \mathrm{~min}$, the DNA solution was purified in silica washing columns (A\&A Biotechnology, Gdynia, Poland). The purified DNA was suspended in $50 \mu \mathrm{L}$ of deionized, DNAase free water and stored at $20^{\circ} \mathrm{C}$.

\section{Polymerase Chain Reaction}

Archaeal 16S rRNA gene fragments were amplified with these primers: $0357 \mathrm{~F}$ with an additional GC clamp, and 0505R, as described by Watanabe et al. [10]. PCR was performed in a Gene-Amp® PCR System 9700 (Applied Biosystems). $50 \mathrm{ng}$ of extracted DNA were used for the PCR mixture, which contained $0.5 \mu \mathrm{M}$ of each primer, $100 \mu \mathrm{M}$ of deoxynucleoside triphosphate (Promega, Wisconsin, U.S.A.), $0.6 \mathrm{U}$ of Hypernova DNA polymerase (DNA-Gdansk, Poland), $3 \mu \mathrm{L}$ of reaction buffer (100 mM Tris- $\mathrm{HCl}$, $500 \mathrm{mM} \mathrm{KCl}, 1.5 \%$ Triton X-100), $1.5 \mathrm{mM} \mathrm{MgCl}_{2}$ and sterile water, for a final volume of $30 \mu \mathrm{L}$. The temperature program for DNA amplification was as follows: $94{ }^{\circ} \mathrm{C}$ for $5 \mathrm{~min} ; 35$ cycles of denaturation at $94{ }^{\circ} \mathrm{C}$ for $45 \mathrm{~s}$, annealing at $58{ }^{\circ} \mathrm{C}$ for $45 \mathrm{~s}$, extension at $72{ }^{\circ} \mathrm{C}$ for $45 \mathrm{~s}$, and a single final elongation at $72{ }^{\circ} \mathrm{C}$ for $10 \mathrm{~min}$. The PCR products were checked via electrophoresis on $1.0 \%$ agarose gels stained with ethidium bromide. Each sample was amplified in triplicate.

\section{Denaturing Gradient Gel Electrophoresis}

Polymerase chain reaction products with a GC clamp were resolved on a $6 \%$ polyacrylamide gel (37.5:1 acrylamide:bisacrylamide) with a gradient ranging from 30 to $60 \%$ of denaturating agent (formamide and urea). Electrophoresis was performed for $15 \mathrm{~h}$ at $60 \mathrm{~V}$ in $1 \times \mathrm{TAE}$ buffer ( $2 \mathrm{M}$ Tris base, $2 \mathrm{M}$ acetic acid, $0.05 \mathrm{M}$ EDTA) using a Dcode system (Bio-Rad Laboratories Inc., Hercules, Canada). The temperature was set at $60{ }^{\circ} \mathrm{C}$. Bands were visualized by staining with 1:10,000 SybrGold (Invitrogen) for $20 \mathrm{~min}$ followed by UV trans-illumination. Images were recorded and analyzed with KODAK 1D 3.6 Image Analysis Software (Eastman Kodak Company, USA). Based on the band intensity on the gel tracks, as indicated by the peak heights of the densitometric curves, a Shannon index of general diversity $\mathrm{H}$ [11] was calculated. The $\mathrm{H}$ value was calculated using the following equation: $\mathrm{H}=-\sum\left(\mathrm{n}_{\mathrm{i}} / \mathrm{N}\right) \times \log \left(\mathrm{n}_{\mathrm{i}} / \mathrm{N}\right)$; where $\mathrm{n}_{\mathrm{i}}$ is the height of the peak and $\mathrm{N}$ the sum of all peak heights of the densitometric curve.

\section{DNA Sequencing}

The $16 S$ rRNA gene bands showing the greatest intensity were excised from the denaturing gel, transferred into $50 \mu \mathrm{L}$ sterile water and frozen at $-20{ }^{\circ} \mathrm{C}$ for $24 \mathrm{~h}$. The samples were thawed at room temperature, and the gel fragments were rubbed mechanically. Eluted PCR products were then re-amplified using the same primer set and purified with a Clean-up kit (A\&A Biotechnology, Gdynia, Poland). Sequencing reactions were performed by Macrogen Europe (Amsterdam, Netherlands) with ABI3730XL (PE Applied Biosystems, Foster City, CA, USA). All reactions were run following the manufacturers' protocols. The obtained sequences were aligned using the ClustalW program and analyzed with the BLAST program.

\section{Statistical Analysis}

To test the null hypothesis of no differences in concentrations of individual VFAs between R-ZM and R-MS, the Tukey HSD test was used (STATISTICA 9.0, StatSoft Inc.), with $\mathrm{p}<0.05$ set as the criteria for significance. Pearson product-moment correlation coefficients were computed to assess the associations between the characteristics of the digestate and the intensity of DNA bands, the biogas production rate and the $\mathrm{CH}_{4}$ content in the biogas (using STATISTICA 9.0).

\section{Calculations}

The efficiency of VS removal was calculated using the following equation Eq. (1):

$\eta_{\mathrm{VS}}=\frac{\left(\mathrm{VS}_{\text {feedstock }}-\mathrm{VS}_{\text {digestate }}\right) \times 100}{\mathrm{VS}_{\text {feedstock }}}$

where $\eta_{\mathrm{VS}}$ is the efficiency of VS removal (\%), and $\mathrm{VS}_{\text {feedstock }}$ and $\mathrm{VS}_{\text {digestate }}$ are the concentrations of VS $\left(\mathrm{g} \mathrm{kg}^{-1}\right)$ in the feedstock and the digestate, respectively.

The efficiency of removal of individual components of both silage feedstocks was calculated with Eq. (2):

$\eta_{i}=\frac{\left(C_{i, \text { feedstock }}-C_{i, \text { digestate }}\right) \times 100}{C_{i, \text { feedstock }}}$

where $\eta_{i}$ is removal efficiency of individual components in the feedstock (RP, RL, NFC, Cel, Hem and ADL) (\%), $C_{i \text {,eeedstock }}$ and $C_{i, \text { digestate }}$ are the concentrations $\left(\mathrm{g} \mathrm{kg}^{-1}\right)$ of individual components in the feedstock and the digestate, respectively. 
The specific biogas production rate was calculated using Eq. (3):

$r_{\mathrm{B}}=\frac{v_{\mathrm{B}}}{V}$

where $r_{\mathrm{B}}$ is the specific biogas production rate $\left(\mathrm{L} \mathrm{L}^{-1}\right.$ day $\left.^{-1}\right)$, $\nu_{\mathrm{B}}$ is the daily biogas production $\left(\mathrm{L} \mathrm{day}^{-1}\right)$ and $V$ is the working volume of the digester $(\mathrm{L})$.

The observed methane yield was calculated using Eq. (4):

$Y_{\mathrm{M}}=\frac{\nu_{\mathrm{B}} \times C_{\mathrm{M}}}{V S_{\text {feedstock }} \times \rho_{\text {feedstock }} \times V_{\text {feedstock }} \times 100}$

where $Y_{\mathrm{M}}$ is observed methane yield $\left(\mathrm{L} \mathrm{g}^{-1} \mathrm{VS}\right), \nu_{\mathrm{B}}$ is the daily biogas production $\left(\mathrm{L} \mathrm{day}^{-1}\right), C_{\mathrm{M}}$ is the concentration of methane in biogas (\%), $\mathrm{VS}_{\text {feedstock }}$ is the concentration of VS in the feedstock $\left(\mathrm{g} \mathrm{kg}^{-1}\right), \rho_{\text {feedstock }}$ is the density of the feedstock (assumed to be $\rho_{\text {feedstock }} \approx 1.0 \mathrm{~kg} \mathrm{~L}^{-1}$ ) and $V_{\text {feedstock }}$ is the volume of the feedstock added to the digester each day $\left(\mathrm{L} \mathrm{day}^{-1}\right)$.

The theoretical yield of methane $\left(Y_{\mathrm{M} \text {, theor }}\right)$ for silage feedstock was estimated using the stoichiometric O'Rourke's equation, as described in detail in Klimiuk et al. [12]. Because only part of the VS are converted to methane, due to the presence of a non-biodegradable fraction in the feedstock, the amount of methane which theoretically could be produced in these experimental conditions $\left(Y_{\mathrm{M}, \mathrm{VSrem}}\right)$ was calculated (Eq. 5) with the assumption that the efficiency of volatile solids removal $\left(\eta_{\mathrm{VS}}\right)$ corresponded to the concentration of the biodegradable fraction in the feedstock.

$Y_{\mathrm{M}, \mathrm{VS}_{\mathrm{rem}}}=\frac{Y_{\mathrm{M}, \text { theor }} \times \eta_{\mathrm{VS}}}{100}$

where $Y_{\mathrm{M} \text {, vSrem }}$ is theoretical methane yield estimated based on VS removal ( $\mathrm{L} \mathrm{g}^{-1} \mathrm{VS}$ ), and $\eta_{\mathrm{VS}}$ is the efficiency of VS removal (\%).

\section{Results and Discussion}

\section{Digestate Performance and Organics Removal Efficiency}

The results of selected indicators of reactor performance are shown in Table 1 . To maintain appropriate alkalinity and $\mathrm{pH}$ in R-ZM and R-MS, $\mathrm{NaOH}$ was added.

The concentration of ammonium nitrogen in silages was low, but both substrates contained proteins that underwent decomposition, resulting in ammonium nitrogen release to digestate. In R-ZM, the concentration of ammonium nitrogen was $117 \mathrm{mg} \mathrm{L}^{-1}$, whereas in R-MS, it was $120 \mathrm{mg} \mathrm{L}^{-1}$, both within the optimal range of $50-200 \mathrm{mg} \mathrm{L}^{-1}$ [13]. In R-ZM, the average concentration of VFAs was $2150 \mathrm{mg} \mathrm{L}^{-1}$, while in R-MS it was $3000 \mathrm{mg} \mathrm{L}^{-1}$.

Although the OLR was similar in both series, the organics (expressed as VS) were removed with higher efficiency during the digestion of $Z$. mays L. silage than during that of M. sacchariflorus. This was due to different loads of individual fibrous and non-fibrous components (Fig. 1). Z. mays L. silage contained a higher concentration of non-fibrous carbohydrates than $M$. sacchariflorus. In contrast, $M$. sacchariflorus had about two times more cellulose and four times more lignin.

Non-fibrous materials were removed more efficiently in R-ZM (RP, 55.6\%; RL, 92.1\%; NFC, 90.2\%) than in R-MS (RP, $51.5 \%$; RL, $48.1 \%$; NFC, $47.8 \%$ ). As for the fibrous materials, hemicellulose was removed less efficiently in R-ZM (68.2\%) than in R-MS (74.1\%). In contrast, cellulose was removed more efficiently in R-ZM (65.4\%) than R-MS (58.2\%). The removal efficiency probably differed because the higher content of lignin in M. sacchariflorus reduced cellulose hydrolysis by two mechanisms: providing a physical barrier that impeded or prevented cellulases from accessing the cellulose, and irreversibly adsorbing and binding these enzymes, thus preventing their action on cellulose. Mussatto et al. [14] have shown that the cellulose conversion ratio (defined as a sum of glucose yield and cellobiose yield) is four times higher after removing lignin and
Table 1 Selected indicators characterizing anaerobic digestion performance

\begin{tabular}{|c|c|c|c|c|c|}
\hline \multirow[t]{2}{*}{ Characteristics } & \multirow[t]{2}{*}{ Units } & \multicolumn{2}{|c|}{ R-ZM (Z. mays L.) } & \multicolumn{2}{|c|}{ R-MS (M. sacchariflorus) } \\
\hline & & Feedstock & Digestate & Feedstock & Digestate \\
\hline VS & $\mathrm{g} \mathrm{L}^{-1}$ & $92.2( \pm 3.6)$ & $25.9( \pm 2.1)$ & $95.1( \pm 5.31)$ & $49.3( \pm 9.8)$ \\
\hline $\mathrm{pH}$ & - & $4.48( \pm 0.17)$ & $7.31( \pm 0.10)$ & $7.5( \pm 0.10)$ & $7.25( \pm 0.12)$ \\
\hline Alkalinity & $\mathrm{mg} \mathrm{CaCO} \mathrm{L}^{-1}$ & - & $7185( \pm 1656)$ & $1240( \pm 9.2)$ & $6315( \pm 1542)$ \\
\hline VFA & $\mathrm{mg} \mathrm{L}^{-1}$ & $2331( \pm 72.7)$ & $2150( \pm 229)$ & $2837( \pm 460)$ & $3000( \pm 495)$ \\
\hline CODs & $\mathrm{mg} \mathrm{L}^{-1}$ & $27,542( \pm 2037)$ & $3059( \pm 709)$ & $21,102( \pm 2277)$ & $3715( \pm 716)$ \\
\hline Ammonium & $\mathrm{mg} \mathrm{NH}_{4}^{+} \mathrm{L}^{-1}$ & $68.6( \pm 1.3)$ & $117.0( \pm 35.8)$ & $28.0( \pm 4.0)$ & $119.7( \pm 34.6)$ \\
\hline Phosphate & $\mathrm{mg} \mathrm{PO}_{4}^{3-} \mathrm{L}^{-1}$ & $131.4( \pm 6.2)$ & $49.8( \pm 13.5)$ & $77.7( \pm 4.1)$ & $42.7( \pm 13.7)$ \\
\hline
\end{tabular}

Standard deviations are given in parentheses 

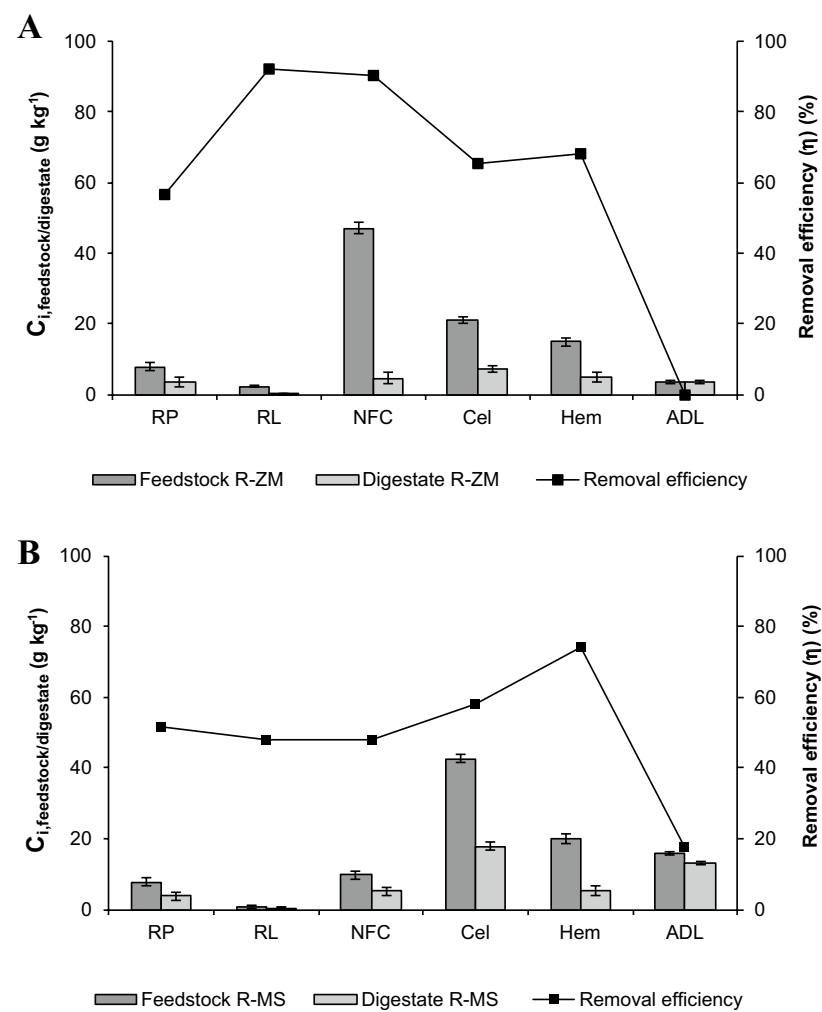

Fig. 1 Composition of the feedstock and percent removal of individual components with a Z. mays (R-ZM) L.; b M. sacchariflorus (R-MS). Error bars represent standard deviations. $R P$ raw protein, $R L$ raw lipids, $N F C$ non-fibrous carbohydrates, $\mathrm{Cel}$ cellulose, Hem hemicellulose, $A D L$ acid detergent lignin
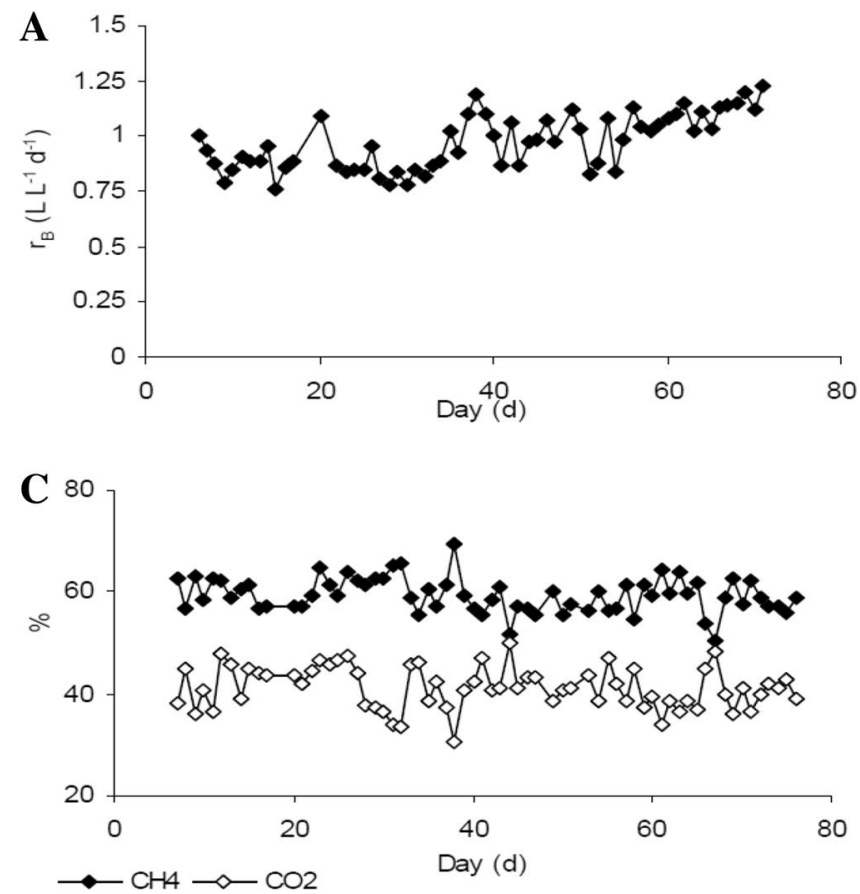

hemicellulose from brewer's spent grain than before removing these substances.

\section{Biogas/Methane Production}

The specific biogas production rate $\left(r_{\mathrm{B}}\right)$ and the percent concentration of methane in biogas are presented in Fig. 2.

The specific biogas production rate of R-ZM increased over time, whereas that of R-MS was stable. The specific biogas production rate of R-MS was half that of R-ZM, indicating that $M$. sacchariflorus is a less efficient substrate. Moreover, during digestion of $M$. sacchariflorus, $\mathrm{CO}_{2}$ concentration increased, whereas that of $\mathrm{CH}_{4}$ decreased. The theoretical and calculated methane yields are presented in Table 2 .

It was found that the ratio of $Y_{\mathrm{M}} / Y_{\mathrm{M}, \mathrm{VSrem}}$ in R-ZM was 0.94, whereas in R-MS it was only 0.69. This means that, with $M$. sacchariflorus as a substrate, degradation of organic compounds and methane production were uncoupled. This uncoupling may have occurred because the methanogens were inhibited by components of $M$. sacchariflorus biomass, or by intermediate metabolites formed during its digestion, or both.

The $M$. sacchariflorus biomass in the present study contained a high concentration of lignin, which based on the measured difference between lignin concentration in the feedstock and that in the digestate, was removed during digestion with an efficiency of $17.7 \%$ (Fig. 1b). Although this is not a direct measurement of intermediates of lignin
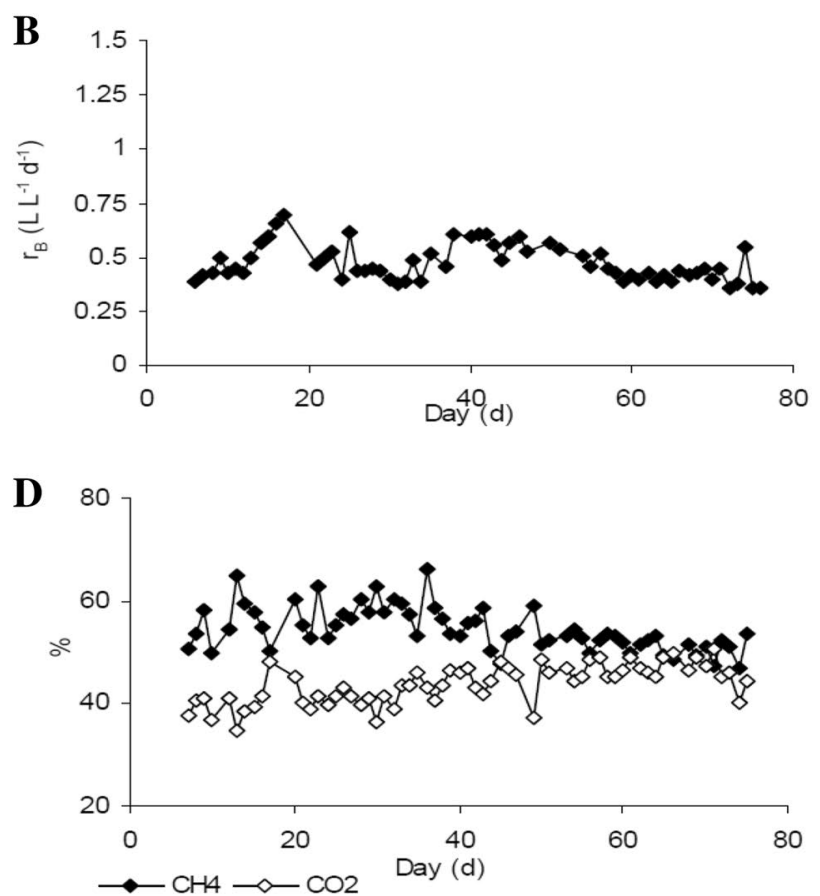

Fig. 2 Specific biogas production rate $\left(r_{\mathrm{B}}\right)$, and $\mathrm{CH}_{4}$ and $\mathrm{CO}_{2}$ content in biogas during digestion of a and c Z. mays L. (R-ZM); b and d M. sacchariflorus (R-MS) 
Table 2 Methane yield during anaerobic digestion of Z. mays L. (R-ZM) and $M$. sacchariflorus (R-MS)

\begin{tabular}{lllc}
\hline Parameters & Unit & R-ZM & R-MS \\
\hline $\begin{array}{l}\text { Efficiency of volatile solids removal }\left(\eta_{\mathrm{VS}}\right) \\
\begin{array}{l}\text { Theoretical methane yield predicted stoichio- } \\
\text { metrically }\left(Y_{\mathrm{M}, \text { theor }}\right)\end{array}\end{array}$ & $\%$ & $72.1( \pm 2.0)$ & $48.0( \pm 7.4)$ \\
$\begin{array}{l}\text { Theoretical methane yield estimated based on VS } \\
\text { removal }\left(Y_{\mathrm{M}, \mathrm{VSrem}}\right)\end{array}$ & $\mathrm{L} \mathrm{g}^{-1} \mathrm{VS}$ & 0.45 & 0.51 \\
$\begin{array}{l}\text { Observed methane yield }\left(Y_{\mathrm{M}}\right) \\
\text { Ratio of } Y_{\mathrm{M}} / Y_{\mathrm{M}, \mathrm{VSrem}}\end{array}$ & $\mathrm{L} \mathrm{g}^{-1} \mathrm{VS}$ & $0.30( \pm 0.05)$ & 0.24 \\
\hline
\end{tabular}

Standard deviations are given in parentheses digestion, recent research has shown that several species of bacteria can degrade lignin under anaerobic conditions $[15,16]$. Kato et al. [17] demonstrated that lignin-derived aromatics are degraded under methanogenic conditions due to cooperation among acetogens, ring-cleaving fermenters/ syntrophs and acetoclastic/hydrogenotrophic methanogens. They showed that acetogenic bacteria enriched from rice paddy field soil can utilize the $O$-methyl groups on these aromatics, but they are unable to degrade the aromatic ring structure, which can be degraded by some sulfate-reducing bacteria and fermentative bacteria. Molinuevo-Salces et al. [18] found that anaerobic sludge from the anaerobic digester of a municipal wastewater treatment plant degraded up to $80 \%$ of lignin under mesophilic conditions when a mixture of swine manure and vegetable waste (50:50\%) was used as feedstock. They also reported that the efficiencies of lignin removal from vegetable waste as sole feedstock and from this waste in a mixture with poultry litter (50:50\%) were $50 \%$ and $35 \%$, respectively, after 80 days of batch experiments. More recently, Candia-Garcia et al. [19] reported that $32.62 \%$ of lignin was removed from rice straw during 60 days of treatment at room temperature in a batch reactor inoculated with rumen content. These efficiencies of lignin removal in these reports are higher than that observed in the present study with $M$. sacchariflorus as a substrate. This difference could be due to the shorter HRT that was used here (45 day) and differences in the recalcitrance of lignin and other lignocellulosic feedstocks. For example, when Triolo et al. [20] studied the influence on biochemical methane potential of the lignin in energy crops and that in animal manure, both alone and in combination, they found that the lignin in energy crops is degraded to a lesser extent than that in animal manure.

It is well documented that the presence of a lignin fraction, especially a low molecular fraction of this substance, induces methanogenic toxicity and inhibits bacterial growth [21]. Rodriguez-Chiang et al. [22] evaluated the methane potential and biodegradability of acetate and lignin-rich pulp mill effluent at different ratios using mesophilic anaerobic sludge as inoculum. They found a negative linear correlation between lignin content and methane yield. The presence of lignin resulted in a $41 \%$ decrease in methane yield when the lignin fraction was increased by a factor of 3 . A negative linear correlation between lignin content and biodegradability was also observed. The inhibiting effect of lignin derivatives on methanogenesis of lignocellulosic biomass was recently reported by Schroyen et al. [23], who found that phenolic compounds released from Miscanthus severely inhibited $\mathrm{AD}$, thus lowering biogas production. Thus, the fact that, in the present study, VS removal efficiency was 1.5-times lower in R-MS than in R-ZM, and the observed methane yield was $33 \%$ lower than that which theoretically could be produced in these experimental conditions could be due to the inhibitory effect of $M$. sacchariflorus lignin.

\section{VFAs Formation}

The profiles of VFA concentrations in R-ZM and R-MS are shown in Fig. 3. With each silage, the concentrations of VFAs during AD were different. In R-ZM the concentration of propionate (Pro) was highest. The ratio of propionate to acetate (Ac) decreased with time, averaging 2.23. The concentration of valerate ( $\mathrm{Va}$ ) was about two times lower than that of isovalerate (i-Va). Isobutyrate (i-Bu) was found sporadically, and an increase in its concentration was accompanied by a decrease in the concentration of propionate. From highest to lowest, the average concentrations of individual VFAs were as follows: $\mathrm{H}_{\text {Pro }}>\mathrm{H}_{\mathrm{i}-\mathrm{Va}}>\left(\mathrm{H}_{\mathrm{Ac}} \cong \mathrm{H}_{\mathrm{Va}}\right)>\mathrm{H}_{\mathrm{i}-\mathrm{Bu}}$; the differences were statistically significant $(\mathrm{p}<0.05)$. The fact that these VFAs were found in these proportions is probably due to the rate constants for their degradation. VFAs are degraded according to first order kinetics, as reported by Wang et al. [24] after investigating AD of pretreated (ultrasonic disintegration, heating, and freezing) and untreated waste activated-sludge. They found that propionate is degraded more slowly than acetate $\left(\mathrm{k}_{\mathrm{HPro}}=0.02878 \mathrm{~h}^{-1}\right.$ and $\mathrm{k}_{\mathrm{HAc}}=0.06119 \mathrm{~h}^{-1}$, respectively). Degradation of isobutyrate is slower than that of butyrate $(\mathrm{Bu})\left(0.04385 \mathrm{~h}^{-1}\right.$ and $0.16098 \mathrm{~h}^{-1}$, respectively); and isovalerate degradation is slower than that of valerate $\left(0.02169 \mathrm{~h}^{-1}\right.$ and $0.04504 \mathrm{~h}^{-1}$, 

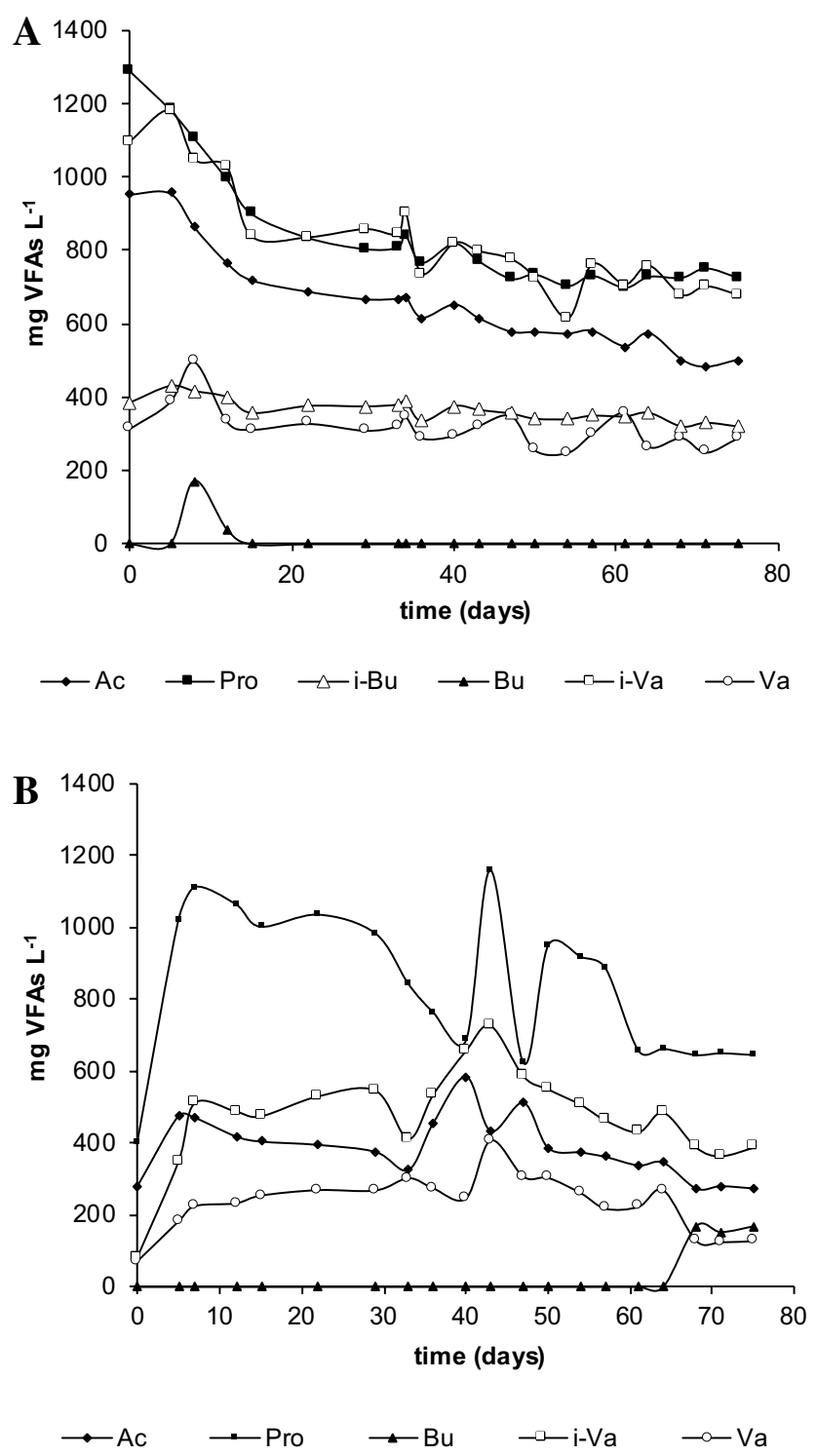

Fig. 3 Profiles of VFAs during digestion of a Z. mays L (R-ZM).; b M. sacchariflorus (R-MS); Ac acetate, Pro propionate, $B u$ butyrate, $i$-Bu isobutyrate, $\mathrm{Va}$ valerate, $i$ - $\mathrm{Va}$ isovalerate

respectively). These differences in rate constants might be due to the different structures of the isoforms.

In R-MS, the concentration of propionate was also higher than that of acetate, but the ratio of propionate to acetate (1.26) was lower than in R-ZM. As with acetate, the isovalerate to acetate ratio was also 1.26 with in R-MS. The concentration of isovalerate did not differ significantly from the concentration of propionate. As the concentration of valerate increased or decreased, so did the concentrations of acetate and propionate. The amount of isobutyrate remained stable over time, averaging $368 \mathrm{mg} \mathrm{L}^{-1}$. The average concentrations of the VFAs were in the following order: $\left(\mathrm{H}_{\text {Pro }} \cong \mathrm{H}_{\mathrm{i}-\mathrm{Va}}\right)>\mathrm{H}_{\mathrm{Ac}}>\left(\mathrm{H}_{\mathrm{Va}} \cong \mathrm{H}_{\mathrm{i}-\mathrm{Bu}}\right)$. In R-MS, the concentrations of isobutyrate and isovalerate were higher than those of butyrate and valerate. Moreover, concentrations of the isoforms of these VFAs were also higher than those in R-ZM (3.08- and 1.7-times higher, respectively). These AD intermediates have been shown to build up when methanogenesis is inhibited by coenzyme $\mathrm{M}$ during $\mathrm{AD}$ of ferulic acid (an intermediate of lignin degradation) [25]. Isovaleric and isobutyric acid are considered to be the most sensitive indicators of digestion imbalance $[4,26]$, and their occurrence in R-MS could have inhibited methanogenic activity. This could also explain why the observed methane yield was $31 \%$ lower than the methane yield that theoretically could be produced in these experimental conditions.

In both digesters, propionate predominated during the entire experiment. Degradation of propionate is known to be the most thermodynamically unfavorable step in the $\mathrm{AD}$ system. It is degraded under a relatively low partial pressure of hydrogen because only under these conditions is the process thermodynamically favorable [26]. Thus, the high concentration of propionate in the digestates from R-ZM and R-MS indicted that propionate degradation was inhibited by a high partial pressure of hydrogen, and also indicated that hydrogenotrophic methanogens were inhibited [27]. This result is consistent with the lower diversity of hydrogenotrophic methanogens in these two digesters (presented in the next section).

\section{The Community Structure of Methanogens in Anaerobic Sludge as Determined by DGGE}

In this study, the diversity and structure of the Archaeal community was determined by PCR-DGGE followed by phylogenetic analysis. DGGE fingerprints of samples from R-ZM and R-MS are shown in Fig. 4. In both series, 24 unique bands were detected by image processing software using the peak heights of the densitometric curves. In R-ZM, the values of the Shannon diversity index increased up to the fifteenth day of the experiment (Fig. 5). After this time, index values oscillated around an average value of $2.82 \pm 0.22$. In R-MS, in contrast, the Shannon index decreased from 2.88 to 2.31 between the twelfth and the last day of the experiment. Our study shows that the type of substrate affects the diversity of methanogens. The influence of substrate on methanogens diversity was previously shown by Dabrowska et al. [28]. In their work, the addition of glycerol and pig slurry to plant silage caused differences in methanogen community structures.

In order to identify the taxa to which the methanogens belonged, the bands with the highest intensity were excised from the DGGE gels and sequenced. The phylogenetic tree of the Archaea, based on 16S rRNA gene sequences, is presented in Fig. 6. 


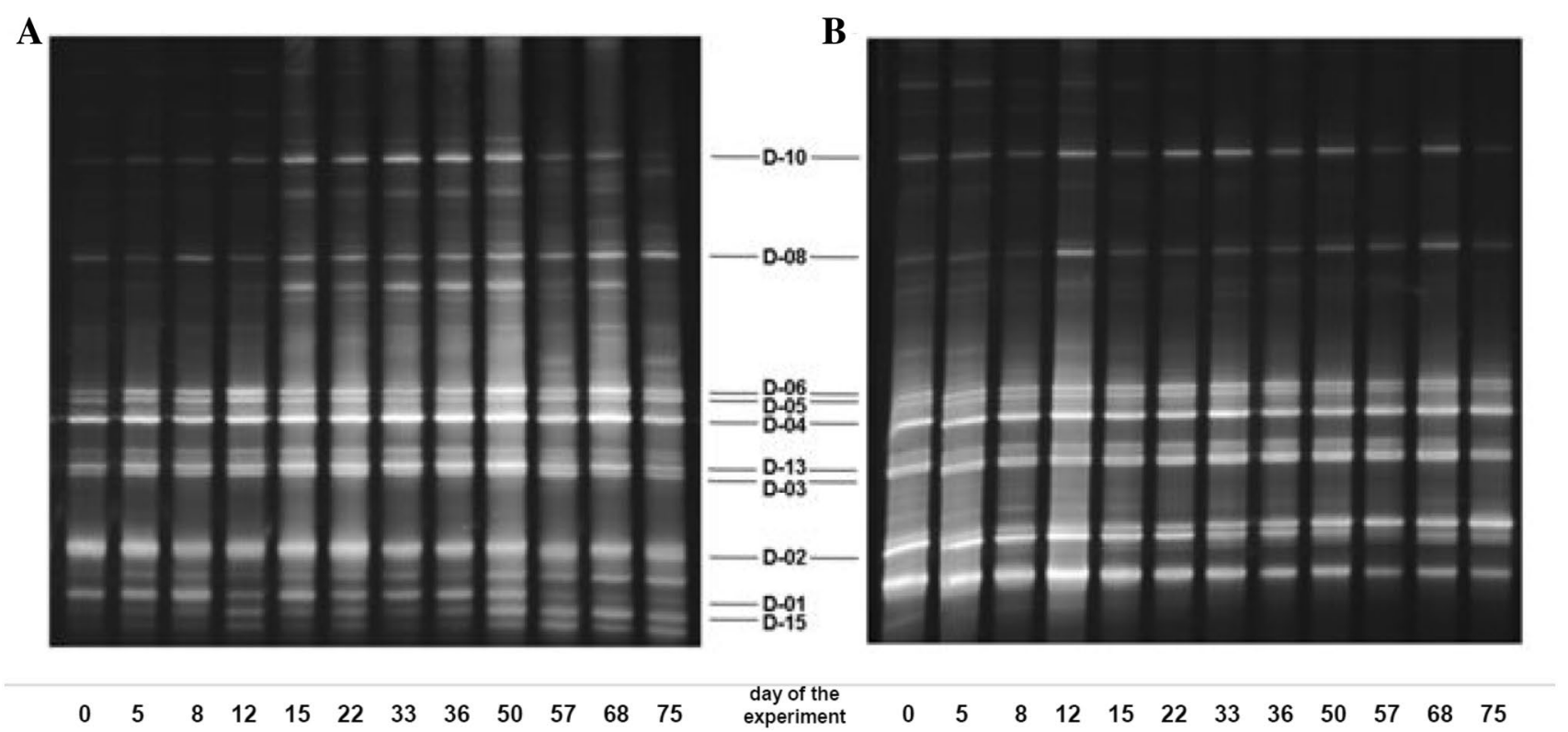

Fig. 4 DNA fingerprints obtained by PCR-DGGE of Archaeal 16S rDNA showing Archaeal community changes during anaerobic digestion of: a Z. mays L. (R-ZM), b M. sacchariflorus (R-MS). The num- ber below each lane shows the sampling day. The most intense bands are indicated by numbers, and their taxa were identified (details in Fig. 6.)

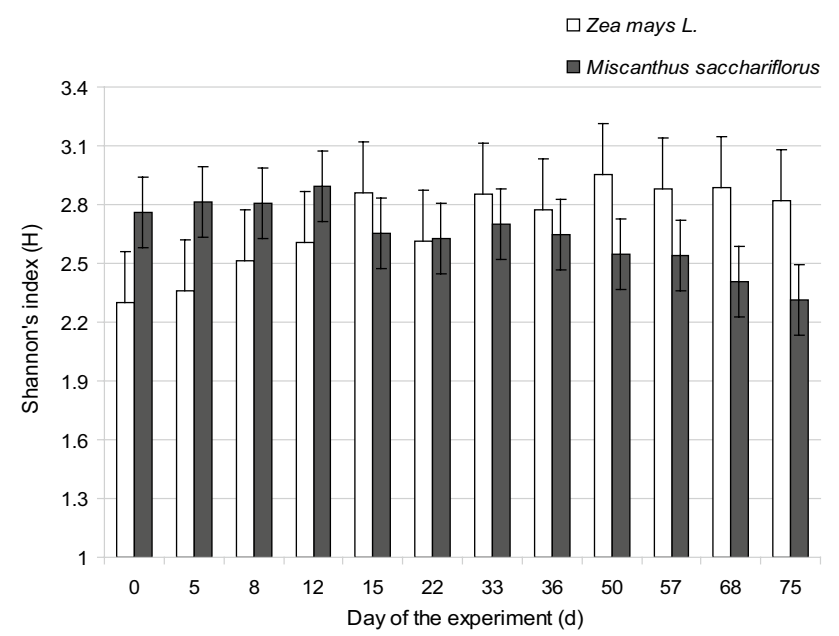

Fig. 5 Changes in Archaeal diversity measured using Shannon's index. Error bars show the standard deviation

With both feedstocks, acetoclastic and hydrogenotrophic methanogens were present. Five bands contained sequences identifying them as belong to the Methanosaetaceae family, which has an affinity for acetate (D-03, D-13, D-06, D-05 and D-15). In addition, band D-02 included a sequence that matched that of Methanosarcina thermophila (JQ346758). Bands D-04 and D-01 were grouped in Methanomicrobiales, which are hydrogenotrophs. Also, DNA sequences derived from the D-10 and D-08 bands formed a distinct clade separated from Methanobacteriales and Methanococcales, and showed close affiliation with a large phylum of Euryarchaeota known as ArcI; whereas band D-08 matched an uncultured ArcI archaeon (CU917025). Microorganisms from the ArcI clade have been recognized as methanogenic, most likely utilizing either $\mathrm{H}_{2} / \mathrm{CO}_{2}$ or formate as a substrate for methanogenesis [29]. They are commonly found in wastewater sludge, sediment and other methanogenic environments.

Marquez et al. [30] studied the diversity of methanogen communities in three single batch digesters operated with marine biomass composed of 59\% sea grasses and $41 \%$ seaweeds during 40 days under thalassic ambient conditions. The reactors were inoculated with cow manure, sea wrack-associated microflora or marine sediment. In all three digesters, hydrogenotrophic methanogens belonging to Methanobacteriales and Methanomicrobiales dominated in the methanogenic populations. Moreover, in the digester inoculated with marine sediment, mixotrophic Methanosarcinaceae co-dominated. Nettman et al. [31] analyzed methanogenic communities in six full-scale biogas plants operated under mesophilic conditions. Hydrogenotrophic Methanomicrobiales predominated in a digester fed with a mixture of $82 \%$ maize silage, $12 \%$ barley grain and $6 \%$ water, working at an HRT of 107 days and an OLR of $3.4 \mathrm{~kg}$ organic dry substance $\mathrm{m}^{-3} \mathrm{day}^{-1}$. In contrast, Methanosaetaceae predominated in a digester fed with a mixture of cattle manure $(76 \%)$, maize silage (13\%), grass silage $(5 \%)$, cattle dung (4\%) and grain (2\%), working at an HRT of 46.9 day and an OLR of $2.5 \mathrm{~kg}$ organic dry substance $\mathrm{m}^{-3}$ day $^{-1}$. Both genera belong to the order Methanosarcinales, which 


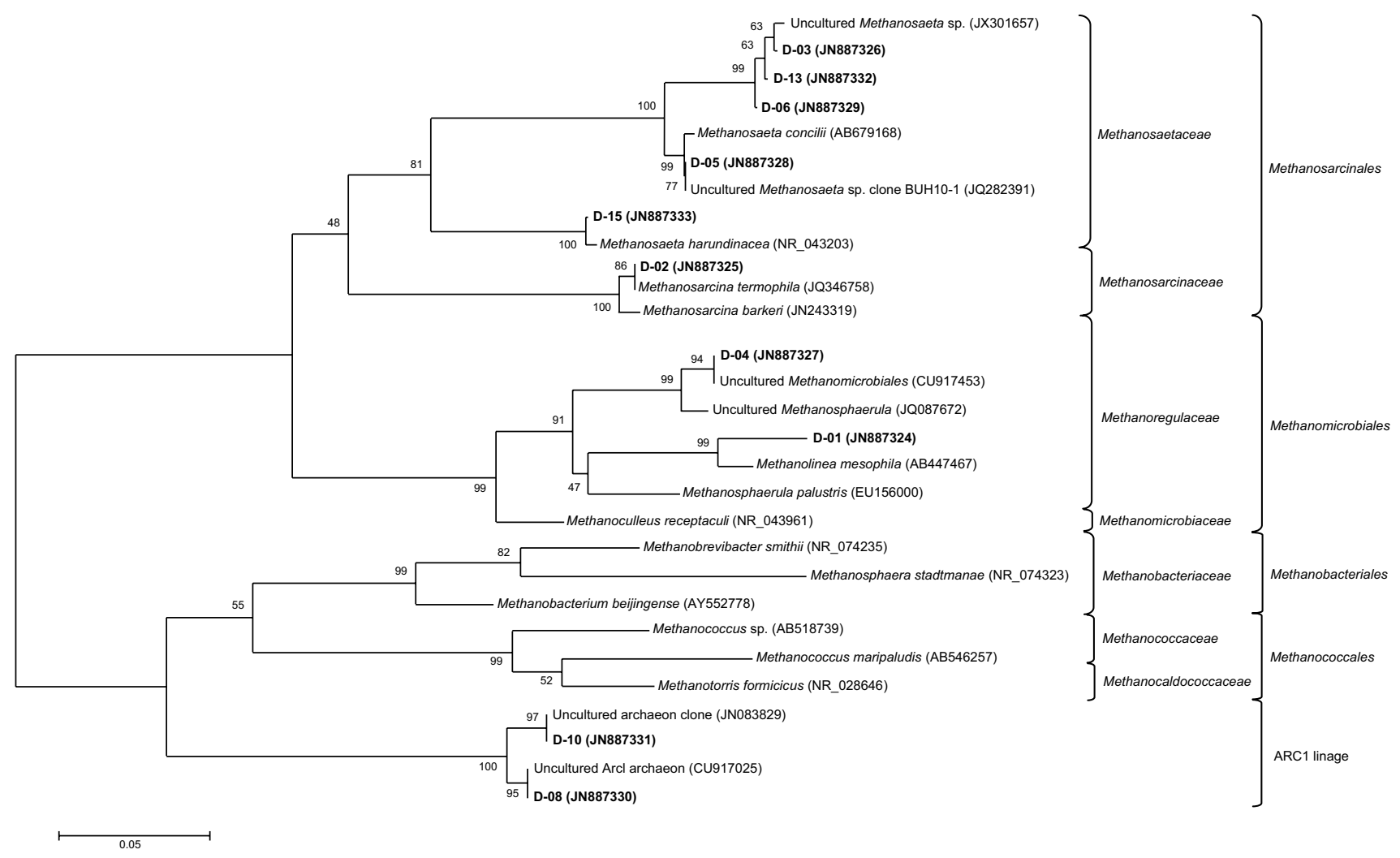

Fig. 6 Neighbor-joining tree showing the phylogenetic affiliation of DGGE band sequences

are acetoclastic methanogens that have been reported to be responsible for approximately $70 \%$ of the methane produced in biogas reactors [17]. Members of the genus Methanosaeta have been reported to dominate in reactors with low levels of $\mathrm{NH}_{3}$ and VFAs [4], whereas Methanosarcina have high metabolic versatility and the ability to use acetate, hydrogen, formate, secondary alcohols and methyl compounds as energy sources [32].

In our research, band D-05, with a DNA sequence affiliated with Methanosaeta concilii (AB679168), was found in both R-ZM and R-MS throughout the experiments. This was probably due to the low ammonium nitrogen concentration, which did not exceed $166 \mathrm{mg} \mathrm{NH}_{4}{ }^{+} \mathrm{L}^{-1}$ in both digesters. $M$. concilii was found to be the most ammonium-sensitive methanogen among a group of pure cultures; it was completely inhibited at a concentration of $560 \mathrm{mg}$ (total) $\mathrm{NH}_{4}^{+} \mathrm{L}^{-1}$ at a suboptimal $\mathrm{pH}$ of 7.0. At consistently higher ammonium concentrations, abundant $M$. concilii are replaced with other methanogens as the microbial community adapts during an operational period [33].

\section{Correlations Between the Concentrations of Individual VFAs and the Abundance of Methanogens}

It was assumed that shifts in Archaeal community structure were related to changes in the concentration of individual VFAs because HRT, OLR, pH, alkalinity and ammonium were held constant throughout the experiments. The intensity of the DGGE bands varied throughout the experiment (Fig. 4), and because PCR-DGGE is a 'semi-quantitative' approach, the differences over time and between groups allowed us to estimate the relative abundance of the Archaea. To evaluate the associations between their abundance and the concentrations of VFAs, Pearson product-moment correlation coefficients were calculated.

There was a weak negative correlation between the intensity of band D-08 (hydrogenotrophic methanogens affiliated with uncultured ArcI) and acetate concentration $(\mathrm{r}=-0.6823, \mathrm{p}=<0.05)$ (Table 3) in R-ZM.

Surprisingly, there was a weak positive correlation $(r=0.6486, p<0.05)$ between the acetate concentration and the intensity of band D-01, whose sequence matched Methanolinea mesophila, belonging to the hydrogenotrophic methanogens. This can happen when hydrogen-consuming methanogens participate in methane production pathways 
Table 3 Pearson correlations between VFA concentrations and DGGE band intensities during anaerobic digestion of $Z$. mays L. (R-ZM)

\begin{tabular}{lllllll}
\hline Bands & Metabolic type & Acetate & Propionate & Isobutyrate & Isovalerate & Valerate \\
\hline D-10 (JN887331) & Hydrogenotrophic & $\mathrm{ns}$ & $\mathrm{ns}$ & $\mathrm{ns}$ & $\mathrm{ns}$ & $0.7708^{* *}$ \\
D-08 (JN887330) & Hydrogenotrophic & $-0.6823^{*}$ & $\mathrm{~ns}$ & $\mathrm{~ns}$ & $\mathrm{~ns}$ & $\mathrm{~ns}$ \\
D-06 (JN887329) & Acetogenotrophic & $\mathrm{ns}$ & $\mathrm{ns}$ & $\mathrm{ns}$ & $0.7291^{*}$ & $\mathrm{~ns}$ \\
D-05 (JN887328) & Acetogenotrophic & $\mathrm{ns}$ & $\mathrm{ns}$ & $\mathrm{ns}$ & $0.7119^{*}$ & $\mathrm{~ns}$ \\
D-04 (JN887327) & Hydrogenotrophic & $\mathrm{ns}$ & $\mathrm{ns}$ & $\mathrm{ns}$ & $\mathrm{ns}$ & $0.6912^{*}$ \\
D-03 (JN887326) & Acetogenotrophic & $\mathrm{ns}$ & $\mathrm{ns}$ & $\mathrm{ns}$ & $0.7122^{*}$ & $\mathrm{~ns}$ \\
D-13 (JN887332) & Acetogenotrophic & $\mathrm{ns}$ & $\mathrm{ns}$ & $\mathrm{ns}$ & $\mathrm{ns}$ & $\mathrm{ns}$ \\
D-02 (JN887325) & Acetogenotrophic & $\mathrm{ns}$ & $\mathrm{ns}$ & $\mathrm{ns}$ & $\mathrm{ns}$ & $\mathrm{ns}$ \\
D-01 (JN887324) & Hydrogenotrophic & $0.6486^{*}$ & $0.6848^{*}$ & $\mathrm{~ns}$ & $\mathrm{~ns}$ & $\mathrm{~ns}$ \\
D-15 (JN887333) & Acetogenotrophic & $\mathrm{ns}$ & $\mathrm{ns}$ & $\mathrm{ns}$ & $\mathrm{ns}$ & $\mathrm{ns}$ \\
\hline
\end{tabular}

For statistically significant results, the value of the linear correlation (Pearson's $r$ ) is presented $n s$ not significant

$* *$, * Significant at $\mathrm{p}<0.01$ and 0.05 , respectively as partners of acetate-oxidizing bacteria. Syntrophic oxidation of acetate has been described by Zinder and Koch [34] as consisting of two reactions: first, oxidation of acetate to hydrogen and carbon dioxide, and second, conversion of hydrogen and carbon dioxide to methane by hydrogenotrophic methanogens. Thus, for successful acetate degradation by this process, the availability of hydrogen is most important. Hydrogen-consuming methanogens belonging to Methanoculleus sp. have been found in all investigations of organisms that participate in mesophilic syntrophic oxidation of acetate [35].

The intensity of band D-01, affiliated with hydrogenotrophic M. mesophila, and the concentration of propionate also correlated positively $(\mathrm{r}=0.6848, \mathrm{p}<0.05)$ (Table 3$)$. Propionate is degraded by acetogenotrophs to produce $1 \mathrm{~mol}$ of acetate, $1 \mathrm{~mol}$ of carbon dioxide and 3 moles of hydrogen.

Thus, it is not surprising that syntrophic interactions between hydrogen-utilizing M. mesophila and acetogenotrophs have been shown in the literature. Sakai et al. [36] isolated M. mesophila from an anaerobic, propionate-degradation enrichment culture that was originally established from a soil sample from a rice field in Taiwan.

The concentration of valerate correlated strongly with the intensity of band D-10 $(r=0.7708, p<0.01)$ and weakly with band D-04 $(r=0.6912, p<0.05)$, both of which are associated with hydrogenotrophic methanogens. This is probably because valerate is most often degraded via $\beta$-oxidation to $1 \mathrm{~mol}$ of acetate, $1 \mathrm{~mol}$ of propionate and $2 \mathrm{~mol}$ of hydrogen [37]. In contrast to the hydrogenotrophic methanogens, bands D-06, D-05 and D-03, with DNA sequences affiliated with acetoclastic methanogens, correlated strongly with the concentration of isovalerate. This "interspecies acetate transfer" may be another type of syntrophic cooperation between anaerobic bacteria, in which acetate has to be kept at minimum concentrations in the presence of hydrogen. The degradation product of isovalerate is mainly acetate. The reaction occurs with $\mathrm{CO}_{2}$ as a co-substrate, producing $3 \mathrm{~mol}$ of acetate and $1 \mathrm{~mol}$ of $\mathrm{H}_{2}$ [37].
Table 4 Pearson correlations between VFA concentrations and DGGE band intensities during anaerobic digestion of M. sacchariflorus (R-MS)

\begin{tabular}{lllllll}
\hline Bands & Metabolic type & Acetate & Propionate & Isobutyrate & Isovalerate & Valerate \\
\hline D-10 (JN887331) & Hydrogenotrophic & $\mathrm{ns}$ & $\mathrm{ns}$ & $\mathrm{ns}$ & $\mathrm{ns}$ & $\mathrm{ns}$ \\
D-08 (JN887330) & Hydrogenotrophic & $\mathrm{ns}$ & $\mathrm{ns}$ & $\mathrm{ns}$ & $\mathrm{ns}$ & $\mathrm{ns}$ \\
D-06 (JN887329) & Acetogenotrophic & $\mathrm{ns}$ & $\mathrm{ns}$ & $\mathrm{ns}$ & $\mathrm{ns}$ & $\mathrm{ns}$ \\
D-05 (JN887328) & Acetogenotrophic & $0.7968^{* *}$ & $\mathrm{~ns}$ & $0.8813^{* *}$ & $0.8671^{* *}$ & $\mathrm{~ns}$ \\
D-04 (JN887327) & Hydrogenotrophic & $\mathrm{ns}$ & $\mathrm{ns}$ & $\mathrm{ns}$ & $\mathrm{ns}$ & $\mathrm{ns}$ \\
D-03 (JN887326) & Acetogenotrophic & $\mathrm{ns}$ & $\mathrm{ns}$ & $\mathrm{ns}$ & $\mathrm{ns}$ & $\mathrm{ns}$ \\
D-13 (JN887332) & Acetogenotrophic & $\mathrm{ns}$ & $\mathrm{ns}$ & $\mathrm{ns}$ & $\mathrm{ns}$ & $\mathrm{ns}$ \\
D-02 (JN887325) & Acetogenotrophic & $0.8772^{* *}$ & $0.8788^{* *}$ & $0.8337 * *$ & $0.8547 * *$ & $0.7732^{* *}$ \\
\hline
\end{tabular}

For statistically significant results, the value of the linear correlation (Pearson's $r$ ) is presented ns not significant

**, *Significant at $\mathrm{p}<0.01$ and 0.05 , respectively 
The DGGE analysis of samples from R-MS suggested that the methanogenic community in these digesters is less diverse than that in R-ZM. (Fig. 4b). Two bands that showed high intensity in R-ZM, band D-15 (affiliated with acetoclastic Methanosaetaceae) and D-01 (affiliated with Methanoregulaceae), were not present in R-MS.

In R-MS, correlations between Methanosarcina abundance and the concentrations of all measured VFAs were statistically significant (Table 4). Franke-Whittle et al. [4] made the same observation when investigating the influence of VFA concentrations on methanogenic communities in mesophilic conditions. In our study, band D-05, closely related to Methanosaeta sp., also had a significant positive correlation with the concentrations of acetate, isobutyrate and isovalerate (Table 4). Roest et al. [38] reported that Methanosarcina and Methanoseta species predominate during anaerobic treatment of paper and pulp mill wastewater.

In the present study, the sum of the concentrations of VFAs was $2150 \mathrm{mg} \mathrm{L}^{-1}(27.2 \mathrm{mM})$ in R-ZM and $3000 \mathrm{mg} \mathrm{L}^{-1}$ (37.5 mM) in R-MS. Ahring et al. [2] found that biogas production from manure was not inhibited by concentrations of individual VFAs up to $50 \mathrm{mM}$. Thus, any variation in biogas production in the present study was probably not due to excessive concentrations of VFAs, as also indicated by the positive correlations between the intensity of DGGE bands and the concentrations of individual VFAs.

\section{Conclusions}

The results of this study indicate that the content of lignocellulosic components in biomass influences the efficiency of biogas synthesis. Organics were removed with higher efficiency during the digestion of $Z$. mays silage, due to the higher content of non-fibrous carbohydrates in this substrate. In addition, non-fibrous materials were removed more efficiently from $Z$. mays than from $M$. sacchariflorus silages. The concentrations of individual VFAs differed slightly between the digesters, but propionate predominated in both. In both digesters, independently of the substrate used, acetoclastic Methanosaeta sp. and Methanosarcina sp. predominated, and hydrogenotrophic methanogens were also detected. The abundance of hydrogenotrophic methanogens strongly correlated with valerate concentration, whereas the abundance of acetoclastic methanogens correlated with isovalerate concentration. To sum up, this study indicates that the presence in a substrate of lignin, or metabolites of lignin degradation, or both, uncouples organics removal and methane production, and influences the structure of the microbial communities responsible for anaerobic digestion.
Acknowledgements This research was financially supported by the Polish Ministry of Science and Higher Education as part of Project No. NN310 209137.

Open Access This article is distributed under the terms of the Creative Commons Attribution 4.0 International License (http://creativeco mmons.org/licenses/by/4.0/), which permits unrestricted use, distribution, and reproduction in any medium, provided you give appropriate credit to the original author(s) and the source, provide a link to the Creative Commons license, and indicate if changes were made.

\section{References}

1. Sawatdeenarunat, C., Surendra, K.C., Takara, D., Oechsner, H., Khanal, S.K.: Anaerobic digestion of lignocellulosic biomass: challenges and opportunities. Bioresour. Technol. 178, 178-186 (2015). https://doi.org/10.1016/j.biortech.2014.09.103

2. Ahring, B.K., Sandberg, M., Angelidaki, I.: Volatile fatty acids as indicators of process imbalance in anaerobic digestors. Appl. Microbiol. Biotechnol. 43, 559-565 (1995). https://doi. org/10.1007/BF00218466

3. Wu, W.M., Jain, M.K., Zeikus, J.G.: Anaerobic degradation of normal- and branched-chain fatty acids with four or more carbons to methane by a syntrophic methanogenic triculture. Appl. Environ. Microbiol. 60, 2220-2226 (1994)

4. Franke-Whittle, I.H., Walter, A., Ebner, C., Insam, H.: Investigation into the effect of high concentrations of volatile fatty acids in anaerobic digestion on methanogenic communities. Waste. Manage. 34, 2080-2089 (2014). https://doi.org/10.1016/j.wasma n.2014.07.020

5. APHA (American Public Health Association): Standard Methods for the Examination of Water and Wastewater, 18th edn. American Public Health Association, Washington (1992)

6. EN ISO 16472:2006. Animal feeding stuffs-determination of amylase-treated neutral detergent fibre content (aNDF)

7. EN ISO 6865:2000. Animal feeding stuffs-determination of crude fibre content-method with intermediate filtration

8. Koch, K., Lübken, M., Gehring, T., Wichern, M., Horn, H.: Biogas from grass silage-measurements and modeling with ADM1. Bioresour. Technol. 101, 8158-8165 (2010). https://doi. org/10.1016/j.biortech.2010.06.009

9. Gilroyed, B.H., Reuter, T., Chu, A., Hao, X., Xu, W., McAllister, T.A.: Anaerobic digestion of specified risk materials with cattle manure for biogas production. Bioresour. Technol. 101, 57805785 (2010). https://doi.org/10.1016/j.biortech.2010.02.077

10. Watanabe, T., Asakawa, S., Nakamura, A., Nagaoka, K., Kimura, M.: DGGE method for analyzing 16S rDNA of methanogenic archaeal community in paddy field soil. FEMS Microbiol. Lett. 232, 153-163 (2004). https://doi.org/10.1016/S0378 -1097(04)00045-X

11. Shannon, C.E., Weaver, W.: The Mathematical Theory of Communication. University of Illinois Press, Urbana (1963)

12. Klimiuk, E., Pokój, T., Budzyński, W., Dubis, B.: Theoretical and observed biogas production from plant biomass of different fibre contents. Bioresour. Technol. 101, 9527-9535 (2010). https://doi. org/10.1016/j.biortech.2010.06.130

13. McCarty, P.L.: Anaerobic waste treatment fundamentals. Part one: chemistry and microbiology. Public Works 95, 107-112 (1964)

14. Mussatto, S.I., Fernandes, M., Milagres, A.M.F., Roberto, I.C.: Effect of hemicellulose and lignin on enzymatic hydrolysis of cellulose from brewer's spent grain. Enzyme Microb. Technol. 43, 124-129 (2008). https://doi.org/10.1016/j.enzmictec.2007.11.006 
15. DeAngelis, K.M., Sharma, D., Varney, R., Simmons, B., Isern, N.G., Markilllie, L.M., Nicora, C., Norbeck, A.D., Taylor, R.C., Aldrich, J.T., Robinson, E.W.: Evidence supporting dissimilatory and assimilatory lignin degradation in Enterobacter lignolyticus SCF1. Front. Microbiol. 280, 1-14 (2013). https://doi. org/10.3389/fmicb.2013.00280

16. Jamaluddin, M.F., Zainol, N., Abdul-Rahmanb, R., Abdul-Ghaffar, N.F., Salihon, J.: Comparison of anaerobic lignin degradation of banana stem waste using mixed culture from Malaysian soil and pure strains from soil culture. Asian J. Microbiol. Biotechnol. Environ. Sci. 16, 551-560 (2014)

17. Kato, S., Chino, K., Kamimura, N., Masai, E., Yumoto, I., Kamagata, Y.: Methanogenic degradation of lignin-derived monoaromatic compounds by microbial enrichments from rice paddy field soil. Sci. Rep. 5, 14295 (2015). https://doi.org/10.1038/srep14295

18. Molinuevo-Salces, B., Gómez, X., Morán, A., García-González, M.C.: Anaerobic co-digestion of livestock and vegetable processing wastes: fibre degradation and digestate stability. Waste Manage. 33, 1332-1338 (2013). https://doi.org/10.1016/j.wasma n.2013.02.021

19. Candia-García, C., Delgadillo-Mirquez, L., Hernandez, M.: Biodegradation of rice straw under anaerobic digestion. Environ. Technol. Innovation. 10, 215-222 (2018). https://doi. org/10.1016/j.eti.2018.02.009

20. Triolo, J.M., Sommer, S.G., Møller, H.B., Weisbjerg, M.R., Jiang, X.Y.: A new algorithm to characterize biodegradability of biomass during anaerobic digestion: influence of lignin concentration on methane production potential. Bioresour. Technol. 102(20), 9395-9402 (2011). https://doi.org/10.1016/j.biortech.2011.07.026

21. Erakovic, S., Jankovic, A., Tsui, G.C., Tang, C.Y., MiskovicStankovic, V., Stevanovic, T.: Novel bioactive antimicrobial lignin containing coatings on titanium obtained by electrophoretic deposition. Int. J. Mol. Sci. 15(7), 12294-12322 (2014). https://doi. org/10.3390/ijms150712294

22. Rodriguez-Chiang, L., Llorca, J., Dahl, O.: Anaerobic co-digestion of acetate-rich with lignin-rich wastewater and the effect of hydrotalcite addition. Bioresour. Technol. 218, 84-91 (2016). https://doi.org/10.1016/j.biortech.2016.06.074

23. Schroyen, M., Van Hulle, S.W., Holemans, S., Vervaeren, H., Raes, K.: Laccase enzyme detoxifies hydrolysates and improves biogas production from hemp straw and miscanthus. Bioresour. Technol. 244, 597-604 (2017). https://doi.org/10.1016/j.biort ech.2017.07.137

24. Wang, Q., Kuninobu, M., Ogawa, H.I., Kato, Y.: Degradation of volatile fatty acids in highly efficient anaerobic digestion. Biomass Bioenergy. 16, 407-416 (1999). https://doi.org/10.1016/S0961 $-9534(99) 00016-1$

25. Healy, J.B., Young, L.Y., Reinhard, M.: Methanogenic decomposition of ferulic acid, a model lignin derivative. Appl. Environ. Microb. 39(2), 436-444 (1980)

26. Shi, X., Lin, J., Zuo, J., Li, P., Li, X., Guo, X.: Effects of free ammonia on volatile fatty acid accumulation and process performance in the anaerobic digestion of two typical bio-wastes. J. Environ. Sci. 55, 49-57 (2017). https://doi.org/10.1016/j. jes.2016.07.006
27. Ketheesan, B., Stuckey, D.C.: Effects of hydraulic/organic shock/ transient loads in anaerobic wastewater treatment: a review. Crit. Rev. Environ. Sci. Technol. 45(24), 2693-2727 (2015). https:// doi.org/10.1080/10643389.2015.1046771

28. Dabrowska, D., Bułkowska, K., Ciesielski, S.: Substrate influence on the structure of methanogenic Archaea communities during anaerobic digestion. Environ. Biotech. 11, 41-47 (2016). https:// doi.org/10.14799/ebms264

29. Rivière, D., Desvignes, V., Pelletier, E., Chaussonnerie, S., Guermazi, S., Weissenbach, J., et al.: Towards the definition of a core of microorganisms involved in anaerobic digestion of sludge. ISME J. 3, 700-714 (2009). https://doi.org/10.1038/ismej.2009.2

30. Marquez, G.P.B., Reichardt, W.T., Azanza, R.V., Onda, D.F.L., Lluisma, A.O., Montaño, M.: N. E. Dominance of hydrogenotrophic methanogens at the peak of biogas production in thalassic digesters. Waste Biomass Valoriz. 6(2), 201-207 (2015). https:// doi.org/10.1007/s1264

31. Bergmann, N.E., Pramschüfer, I., Mundt, S., Plogsties, K., Herrmann, V., Klocke, C.: M.: Polyphasic analyses of methanogenic archaeal communities in agricultural biogas plants. Appl. Environ. Microbiol. 76, 2540-2548 (2010). https://doi.org/10.1128/ AEM.01423-09

32. Kendall, M.M., Boone, D.: The order Methanosarcinales. In: Dworkin, E. (ed.) The Prokaryotes, pp. 244-256. Springer, New York (2006)

33. Calli, B., Mertoglu, B., Inanc, B., Yenigun, O.: Methanogenic diversity in anaerobic bioreactors under extremely high ammonia levels. Enzyme Microb. Technol. 37, 448-455 (2005). doi.https ://doi.org/10.1016/j.enzmictec.2005.03.013

34. Zinder, S.H., Koch, M.: Non-acetoclastic methanogenesis from acetate: acetate oxidation by a thermophilic syntrophic coculture. Arch. Microbiol. 138, 263-272 (1984). doi.https://doi. org/10.1007/bf00402133

35. Schnürer, A., Zellner, G., Svensson, B.H.: Mesophilic syntrophic acetate oxidation during methane formation in biogas reactors. FEMS Micriobiol. Ecol. 29, 249-261 (1999). doi.https://doi. org/10.1016/S0168-6496(99)00016-1

36. Sakai, S., Ehara, M., Tseng, I.C., Yamaguchi, T., Bräuer, S.L., Cadillo-Quiroz, H., et al.: Methanolinea mesophila sp. nov., a hydrogenotrophic methanogen isolated from rice field soil, and proposal of the archaeal family Methanoregulaceae fam. nov. within the order Methanomicrobiales. Int. J. Syst. Evol. Microbiol. 62, 1389-1395 (2012). doi.https://doi.org/10.1099/ijs.0.035048-0

37. Batstone, D.J., Pind, P.F., Angelidaki, I.: Kinetics of thermophilic, anaerobic oxidation of straight and branched chain butyrate and valerate. Biotechnol. Bioeng. 84, 195-204 (2003). doi.https://doi. org/10.1002/bit.10753

38. Roest, K., Heilig, H.G., Smidt, H., de Vos, W.M., Stams, A.J., Akkermans, A.D.: Community analysis of a full-scale anaerobic bioreactor treating paper mill wastewater. Syst. Appl. Microbiol. 28(2), 175-185 (2005). https://doi.org/10.1016/j.syapm .2004 .10 .006 